\title{
Disparidades e dinâmicas territoriais no Brasil
}

\section{Herve Thery ${ }^{1}$ \\ Neli Aparecida de Mello-Thery ${ }^{2}$}

Resumo: A crescente potencia dos computadores pessoais, a sofisticação dos softwares de estatística e cartografia e a disponibilização na internet de dados abundantes, detalhados e gratuitos proporcionam novas dimensões à cartografia temática: o artigo emprega estas novas possibilidades ao tema das disparidades e dinâmicas territoriais no Brasil, adiantado alguns elementos da segunda edição do Atlas do Brasil (Théry e de Mello, 2005), ponto de partida para análise da atual realidade brasileira.

Palavras-chave: cartografia temática, disparidades, dinâmicas territoriais, Brasil

\section{Disparities and territorial dynamics in Brazil}

Abstract. The increasing power of personal computers, the sophistication of statistical and mapping software and the availability on the Internet of abundant, detailed and free data give new dimensions to thematic cartography: this article applies the new possibilities to the issue of disparities and territorial dynamics in Brazil, anticipating some maps of the second edition of the Atlas do Brazil (Théry and de Mello, 2005), as a starting point for analysis of the current Brazilian reality.

Key-Words: thematic cartography, disparities, territorial dynamics, Brazil.

\section{INTRODUÇÃO}

Com a crescente potencia dos computadores pessoais, a sofisticação dos softwares de estatística e cartografia (livres ou com preço extremamente reduzido para o mundo acadêmico) e, sobretudo com a disponibilização na internet de dados abundantes, detalhados e gratuitos, a cartografia tematica tomou novas dimensões e o presente artigo sem pretender ser um "estado da arte" deste campo de atuação - aplica estas novas possibilidades ao tema das disparidades e dinâmicas territoriais no Brasil, adiantado alguns elementos da segunda edição do Atlas do Brasil (Théry e de Mello, 2005) a ser publicada na EDUSP em 2013.

\footnotetext{
${ }^{1}$ Graduação em História e em geografia pela Université Paris 1 (Panthéon-Sorbonne), mestrado em Geografia pela Université Paris 1 (Panthéon-Sorbonne), doutorado em Geografia pela Université Paris 1. pesquisador do Centre National de la Recherche Scientifique, professor visitante da Universidade de São Paulo, pesquisador convidado da Universidade de Brasília (CDS), Diretor do OHM (Observatoire Hommes-milieux) Oyapock CNRS-INEE. E-mail: herve.thery@usp.br

${ }^{2}$ Graduacão em Geografia pela Universidade Federal de Goiás, em 2008 obteve sua livre docência na Universidade de São Paulo, mestrado em Arquitetura e Urbanismo pela Universidade de Brasília e em Géographie et Pratique du Développement - Université de Paris OuestNanterre-La Defense e doutorado em Geographie - Universite de Paris Ouest-Nanterre-La Defense e em Geografia Humana, pela Universidade de São Paulo. Professora no Curso de gestão ambiental EACH e programa de pos-graduação em geografia humana DegeoFFLCH. E-mail: namello@usp.br
} 
Ao adotar esta perspectiva como ponto de partida para análise da atual realidade brasileira, podemos nos apoiar em vários estudiosos destes assuntos. A literatura sobre disparidades (ou desigualdades, contrastes, oposições, etc.) é imensa, mas a dinâmica é um conceito que tem sido menos utilizado no âmbito dos estudos geográficos.

Normalmente a problemática das disparidades vem acompanhada de um qualificativo: sejam regionais, sociais, educacionais ou de saúde. O primeiro conjunto de diferenças relaciona-se ao modelo de desenvolvimento economia do país e suas consequências sobre a população e sobre os territórios das distintas regiões. Neste contexto resgataremos os primeiros, por serem os mais significativos para a geografia regional.

Nascido da ideia de que de que as transformações se refletem no território por meio de novas configurações, sendo estas, resultantes das dinâmicas provocadoras de tais transformações. Normalmente é o movimento das populações e das atividades econômicas, e que se fundamentam - via várias mediações - na abordagem estruturalista. Aproxima-se conceitualmente do debate a respeito dos processos de terriorialização-desterritorializaçãoreterritorialização, porém seus fundamentos apoiam-se em outra base teórica (Deleuze, Guatari, e no Brasil, Haesbaert).

Brunet (2004) fala em estruturas territoriais marcadas pela ação de seis tipos de agentes que englobam os indivíduos, as famílias e seus terrenos de ação; os grupos de interesse, de dominante étnica ou cultural, corporações, associações; as empresas que possuem informações e perfis específicos, suas estratégias e suas redes e influências; em terceiro lugar, o Estado que deveria assegurar a redistribuição de oportunidades entre ricos e pobres ou entre regiões ricas e regiões pobres; as coletividades territoriais (como são chamadas as autoridades locais na França) e as organizações internacionais, especialmente a União Européia. Estes dois últimos tipos de agentes são bastante atuantes nos contextos francês e europeu. Para ele há princípios fundamentais e permanentes que regem estas estruturas territoriais e seus agentes e as qualifica em a) repartição ou redistribuição (do estoque de riquezas); b) Criação do novo a partir das condições locais vão permitir essa criação; c) Reparação, que visa reparar as desigualdades; d) a Proteção ambiental, envolvendo o patrimônio, a paisagem e a cultura e finalmente, a compensação das rupturas, mudanças das trajetórias e de políticas por meio da negociação entre os agentes do Estado e da região. Assim, entendemos que a compreensão de uma determinada região depende de identificar o motor de sua dinâmica, seja ela positiva ou negativa, configurando as regiões ganhadoras 
e perdedoras. Incluem-se na compreensão desta dinâmica os principais agentes e os princípios fundamentais que devem reger a ação sobre o espaço. Apontamos que, a dinâmica negativa demonstra territórios em crise, incapazes de criar mecanismos de estimulo à economia. Há, portanto, uma estreita relação entre a economia, suas dinâmicas e a sociedade que se reflete sobre o espaço e que podem ser causadoras de disparidades ou, contrariamente, podem servir para tornar mais igualitária à região em questão.

Quanto às dinâmicas, podemos destacar dois pontos de vista: Turner e Monbeig. Algumas ideias de Frederick Jackson Turner (1893, in Smith, Neil, 2007) que, em seu ensaio "The significance of the frontier in American history", analisava o mito da fronteira na conquista do Oeste, considerada o embrião do nacionalismo estadunidense:

"O desenvolvimento americano exibiu não apenas um avanço sobre uma linha única, mas um retorno a condições primitivas em uma linha de fronteira que avança continuamente, e um novo desenvolvimento para aquela área [grifo nosso]. O desenvolvimento social americano tem reiniciado continuamente na fronteira... Neste avanço, a fronteira é o limite externo deste movimento - o ponto de encontro entre a barbárie e a civilização... O mundo selvagem tem sido perpassado por linhas de civilização que são cada vez mais numerosas".

Considerava o embate entre a natureza e a necessidade de domínio do mundo hostil pelo homem de maneira a criar um espaço habitável. Com outro ponto de vista ligado aos processos mais dinâmicos, Monbeig $(1952 ; 1981)$ afirmava que para explicar a organização do espaço geográfico e os fenômenos que a constituem, era preciso compreender os processos marcadores dos movimentos das franjas pioneiras. Foi o termo utilizado por ele para definir os sistemas de modificações sociais e econômicas na organização do espaço geográfico, que ocorriam em áreas de baixas densidades populacionais e econômicas. $\mathrm{Na}$ literatura atual tem sido mais frequente o uso do termo "frentes pioneiras". para identificar movimentos de incorporação de novas regiões na economia nacional, caracterizar tanto uma sociedade em movimento como a ação estruturadora do Estado. A mesma se percebe claramente nas "terras novas" e representa, sobretudo, a vontade de povoamento dessas terras do que uma política explicita de crescimento da economia, respaldando Monbeig quanto ser a frente pioneira um assunto de Estado (1981) estimulando um processo de dinâmicas sociais, econômicas e territoriais. 
É a partir da ideia de dinâmica territorial, expressa pelo movimento continuo de inserção de novas terras e na formação de um novo desenvolvimento para tais áreas, que iremos analisar alguns fenômenos recentes, destacando as profundas disparidades que marcam o território brasileiro.

Tais dinâmicas são expressas no tempo e no espaço. Mostram no tempo os processos que se desenvolvem no país, apontando a transição, a evolução da sociedade local e no tempo, as tendências de ocorrência de determinados fenômenos, que podem ser estruturantes ou reestruturantes para o desenvolvimento de um dado local.

Resgatamos ainda outros autores que recentemente tratam da questão das dinâmicas. Em Portugal, João Ferrão (2012) ao analisar as informações do Censo de 2001, aponta que essas permitem verificar as alterações ocorridas no país entre os dois censos e como as mesmas podem refletir a existência de trajetórias de desenvolvimento, regionalmente diferenciadas. Para ele,

$$
\begin{aligned}
& \text { "as trajetórias de evolução permitem contextualizar as dinâmicas } \\
& \text { detectadas. De facto, mais do que desenhar um retrato minucioso do } \\
& \text { presente, interessa-nos entender o significado das mudanças verificadas } \\
& \text { nestes últimos anos à luz dos movimentos estruturais que caracterizam a } \\
& \text { evolução recente da sociedade portuguesa". }
\end{aligned}
$$

Os pesquisadores que integram a Rede de Desenvolvimento Territorial e Integração Regional (ReDeTIR), tem se aprofundado na inter-relação entre as dinâmicas territoriais e o processo de desenvolvimento sustentável. Quando se trata de dinâmicas vinculadas à questão agrária, ou ao desenvolvimento territorial ou ainda à problemática escalar das dinâmicas territoriais do desenvolvimento, o uso de tal abordagem por redes de pesquisadores e laboratórios de pesquisa torna-se mais comum. Destacam-se, entre outros, Ruckert (2006 2008, 2011), Rambo (2011), a revista Sociologias (2004) que publicou o dossiê "Dinâmicas territoriais e desenvolvimento sustentável", organizado por Ivaldo Gehlen (UFRGS) e Alberto Riella (Universidad de la Republica, Uruguai). Além destes, é oportuno mencionar o grupo "Geografia e dinâmicas territoriais do desenvolvimento na Amazônia no século XXI", no âmbito da Associação Nacional de Pós-graduação em Geografia.

Destacamos ainda Verdi e Pires (2008) que assumem estar a dinâmica territorial estreitamente vinculada ao desenvolvimento regional, considerando essa 


\begin{abstract}
"como uma forma espacial de comportamento social, e o desenvolvimento local e regional, entendido como um processo de mudança social dinamizado por expectativas de sistemas e arranjos produtivos de pequenas e médias empresas, territorialmente localizadas e geradoras de emprego e renda".
\end{abstract}

Para eles esta relação expressa a possibilidade de ação coletiva estratégica capaz de mobilizar instituições, organizações, planos, recursos e agrupamento de empresas, associadas às suas capacidades de intervirem na oferta de recursos.

Henri Acserald (2010) organizou o livro Cartografia Social e Dinâmicas Territoriais: marcos para o debate, no qual ressalta as experiências de populações indígenas e quilombolas após entenderem que deviam tomar em mãos as informações de seus espaços, (re)mapeando-os como elementos fundamentais para o reconhecimento de suas terras tradicionais. Estes aspectos foram valorizados pela convenção da OIT (1989), ratificada pelo Brasil, a qual estabelece a base legal para reconhecimento da autodeterminação, das terras tradicionais e dos direitos culturais das populações tradicionais, indígenas e quilombolas.

Consideramos, portanto, que se as dinâmicas engendram disparidades é preciso o uso de mecanismos capazes de resolvê-las. Assim, nas décadas finais do século passado, buscava-se por meio do ordenamento estimular o desenvolvimento territorial e local. Na atualidade, enfatiza-se a tensão entre o global e o local, tomando-se o ordenamento como promoção dos territórios locais. A quem cabe implantar estes mecanismos?

\title{
MÉTODO(S)
}

Da mesma maneira que no Atlas do Brasil: Disparidades e dinâmicas do território (EDUSP 2005), adotamos a cartografia temática baseada na análise estatística como método de investigação e interpretação do dinamismo espacial do país e das suas formas de interação com as disparidades sociais. Tenta-se por meio da construção das imagens temáticas, de apreender contrastes do território, seus condicionantes e principalmente em expressar suas tendências e movimentos dominantes.

Neste artigo pretende-se apontar as tendências identificadas a partir das novas dinâmicas ressaltadas pela analise de dados recentes, principalmente do IBGE (Censo demográfico de 2010, Perfil dos municípios brasileiros 2011), mas também de outras entidades (Banco Central, Caixa Econômica Federal, IPEA, INCRA). 
Os softwares usados para a análise estatística e cartografica são Philcarto, software escrito por Philippe Waniez (acessível gratuitamente na internet no endereço http://philcarto.free.fr/) e Cartes et Données, da firma francesa Articque (acessível para o mundo acadêmico no âmbito do programa geocampus, http://www.geocampus.com/).

\section{RESULTADOS}

A série histórica que retrata a evolução do PIB por Estado de até 2005 permite identificar o seu crescimento e a incorporação de terras novas à economia brasileira: em 1939 se mantinha claramente a figura do "arquipélago Brasil" (Théry, 2012) identificando os pesos na ordem descrescente - dos centros - bem separados - paulista, carioca, mineiro, seguida pelos sul rio-grandense, paranaense, baiano e pernambucano enquanto todo o centro oeste e norte do país ficavam com produção de riqueza imperceptível no mapa. Apesar de se manter uma forte concentração no sul-sudeste, é a partir dos anos 1990 que os valores adicionados à economia tornam-se importantes em todos os estados brasileiros. Com o passar do tempo novas regiões passam a serem visíveis no mapa, mas ficam muito aquém das regiões centrais, princialmente o Estado de São Paulo, cuja predominância fica cada vez mais forte: a dinâmica territorial dominante no Brasil nestes 65 anos é sem duvida um crescimento concentrado da riqueza nacional.

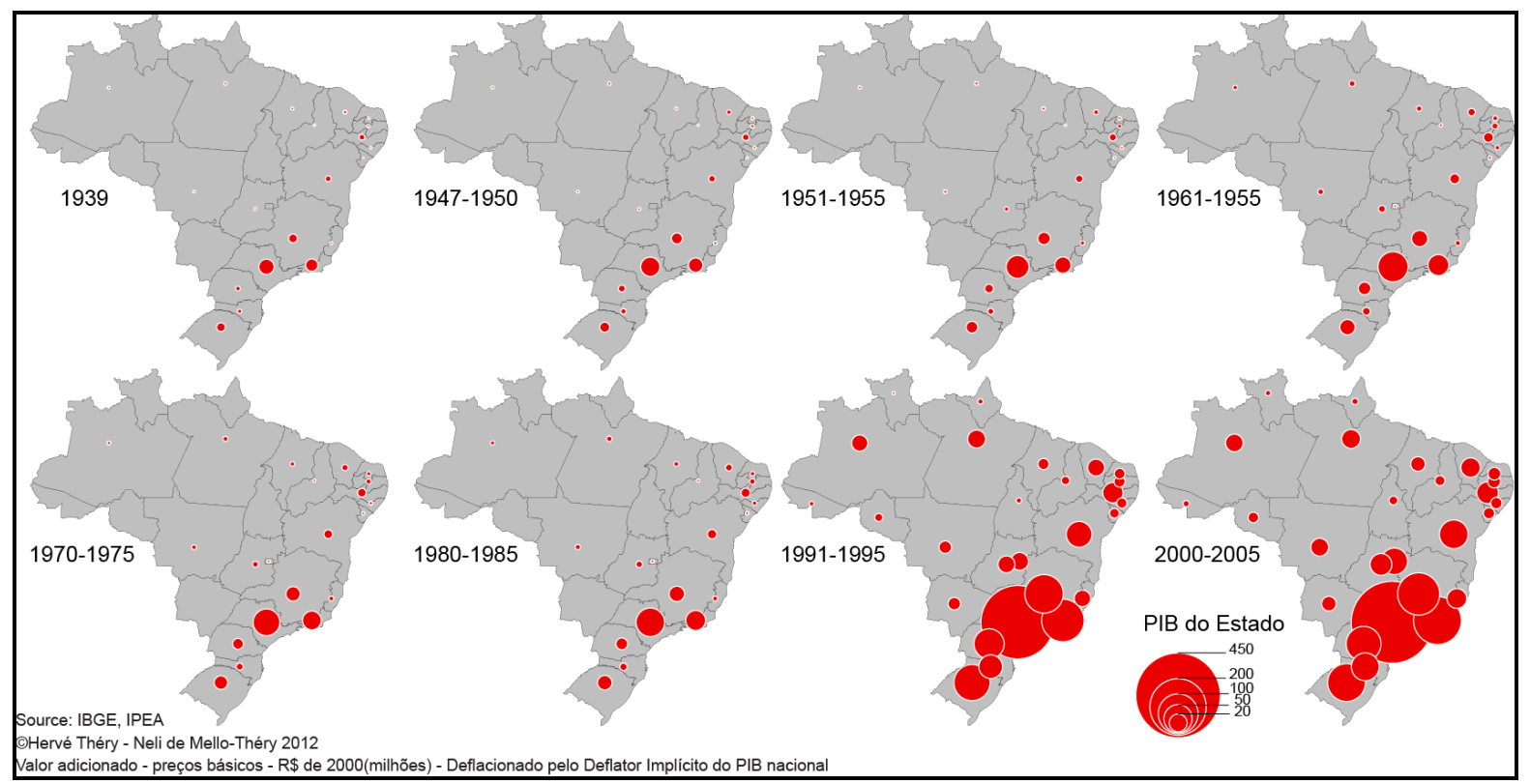

Figura 1 Evolução do PIB 1939-2005 


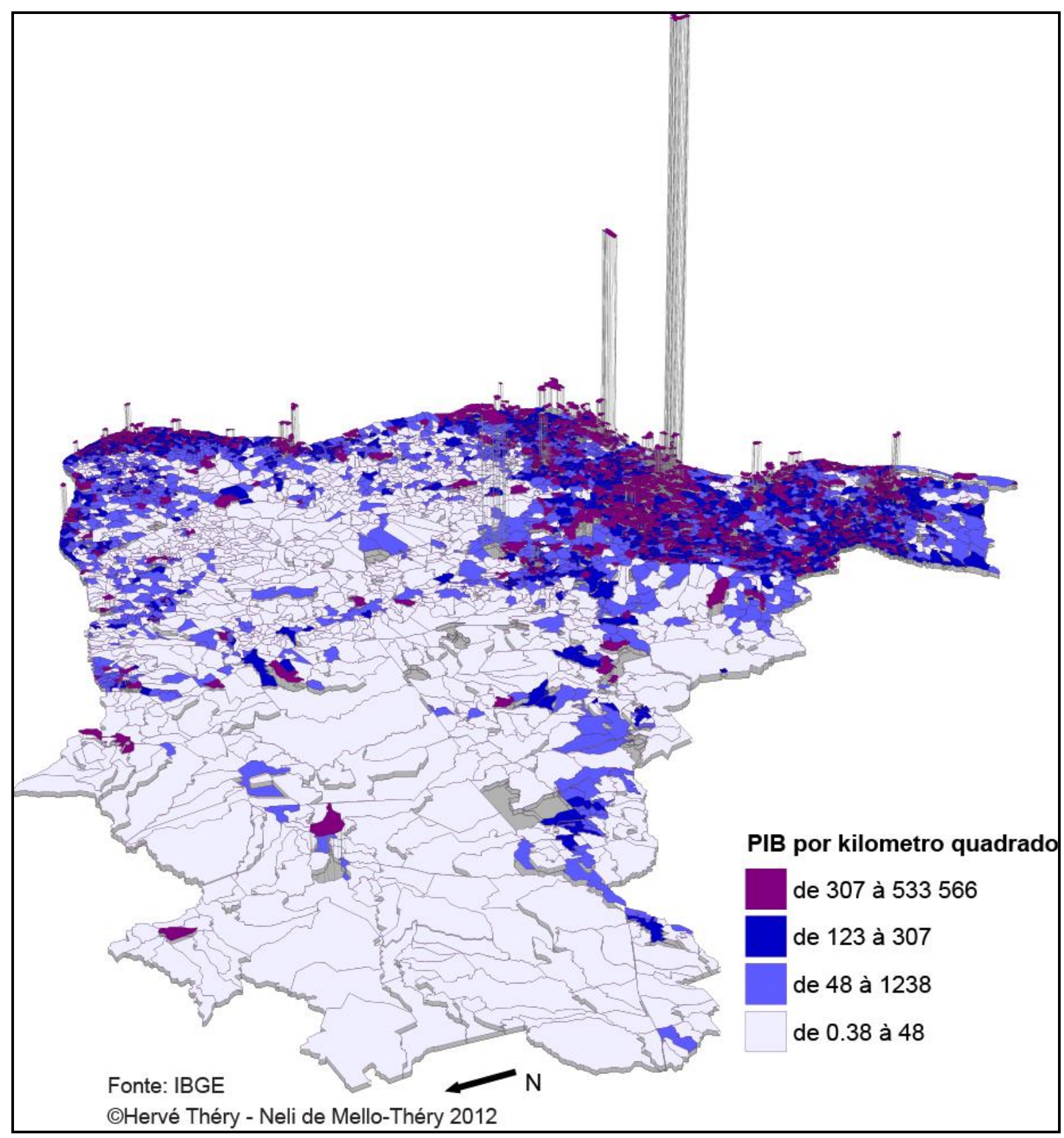

Figura 2 PIB e território

Servindo-se da produção de riqueza no país medida pelo clássico indicador Produto Interno Bruto, por município, verifica-se a primeira grande disparidade no território. Enquanto a representação em terceira dimensão "destaca" literalmente as principais metrópoles e especialmente São Paulo, estabelecendo-se a proporção do PIB por quilometro quadrado, vê-se primeiramente que a maior concentração ocorre no grande bloco formado pelos municípios das regiões sudeste e sul, seguido por todos aqueles localizados na costa brasileira, desde o estado do Ceará até o arroio Chuí.

De maneira mais dispersa aparecem alguns agrupamentos acompanhando os traçados de algumas rodovias como a Belém-Brasília (BR153), a Brasília-Acre (BR364) e o trecho mato- 
grossense da Cuiabá-Santarém (BR163). O mapa dá a impressão que o PIB "anda" ao longo das rodovias, pois alinhamentos de municípios mais prósperos aparecem ao longo dos eixos Belém-Brasília, Cuiabá-Acre, Cuiabá-Santarém, desenhando tentáculos que adentra a Amazônia a partir do Sudeste.

Outro conjunto de municípios onde este indicador se sobressai é acompanhando o curso do rio Amazonas, desde Manaus a Santarém. Constituindo situações peculiares, localizam-se em ambos os municípios atividades econômicas exclusivas como a Zona Franca de Manaus e o porto da Cargill. A Zona Franca de Manaus, existente desde 1957 (lei no 3173) como um "porto livre", passou a conceder incentivos fiscais em 1967 (decreto-lei no 288) visando à criação de um parque industrial (posteriormente agropecuário e comercial) em região de fronteira. Como resultado, o PIB desta zona representava $75 \%$ do que era produzido no Estado, no inicio dos anos 1990. A concessão da primeira licença venceria em 1997 e foi prorrogada para 2007 e posteriormente para 2013. Em Santarém, a instalação de porto graneleiro foi aprovada em 1999, mas a Cargill inicia sua operação somente em 2003. A empresa participa da Moratória da Soja, compromisso entre Governo federal e empresas, que visa a não comercialização de soja produzida em áreas desmatadas depois de julho de 2006.

De um indicador territorial para um social, analisamos a distribuição de bens presentes nos domicílios brasileiros, a partir dos dados do Censo IBGE 2010.

As variáveis escolhidas foram presença do rádio, televisão, máquina de lavar roupa, geladeira, microcomputador, microcomputador com internet, motocicleta para uso particular, automóvel para uso particular - adotou-se quatro categorias (menos equipado que a média, menos equipado que a média exceto motocicleta, um pouco mais equipado que a média, especialmente geladeira e motocicleta e, finalmente, mais equipado que a média, exceto motocicleta). 


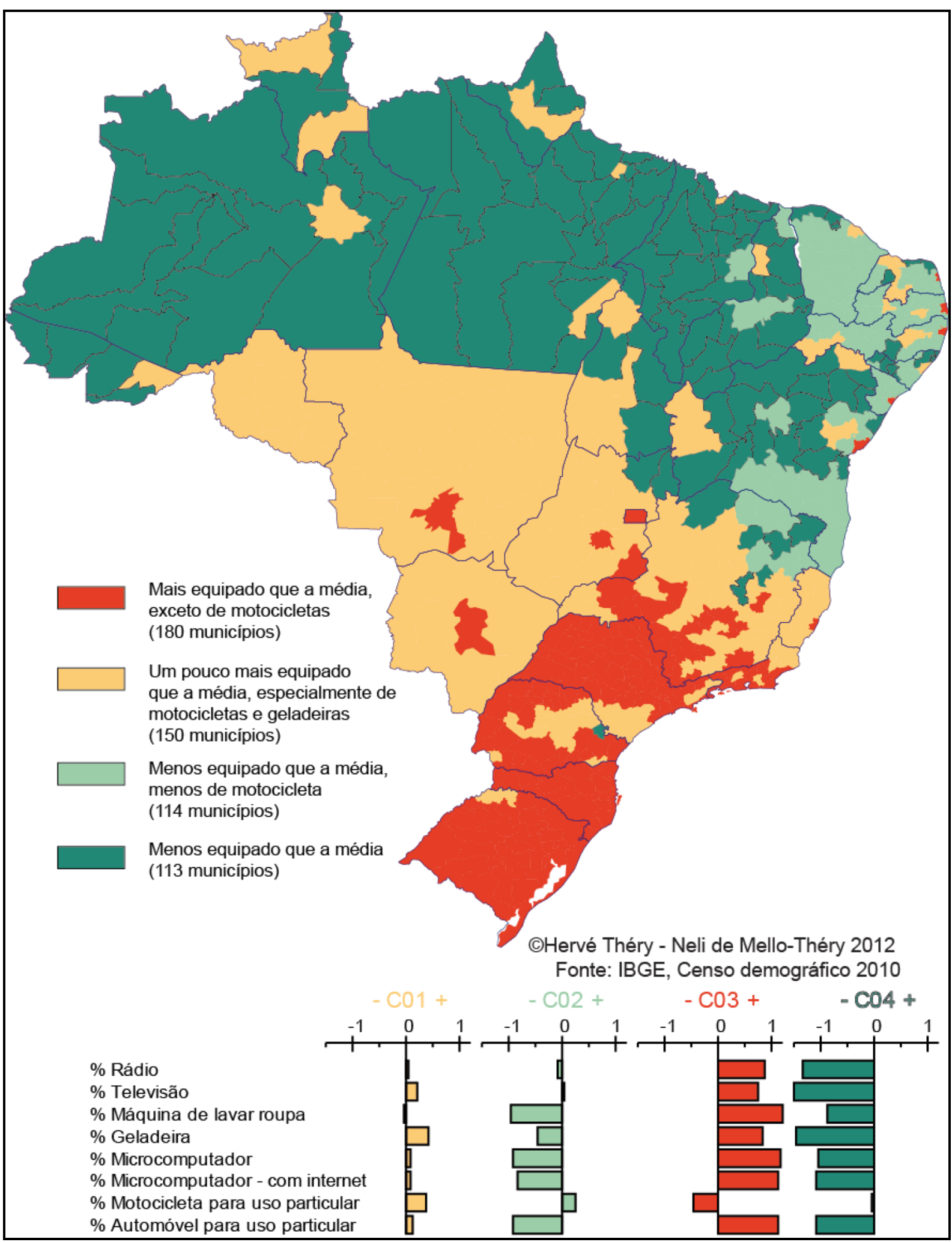

Figura 3 Equipamento dos domicílios

Agregando-se as variáveis por microrregiões e fazendo uma análise de clusters (método presente - e permitindo a sua cartografia - no software Philcarto) aparecem quatros grandes áreas, opondo-se duas delas: a) a que ressalta os domicílios mais equipados que a média, menos no quesito motocicletas, ela concentra-se nos três Estados do sul do país, em São 
Paulo, parcialmente no Rio de Janeiro, Minas Gerais, Distrito Federal e nas regiões de Goiânia, Cuiabá e Campo Grande; b) a que destaca uma população um pouco mais equipada que a média, especialmente com geladeira e motocicleta, concentrando-se nos estados da região centro-oeste (Goiás, Mato Grosso do Sul, Mato Grosso) parcialmente nos estados do Tocantins, Minas Gerais, Espirito Santo e Rondônia e algumas microrregiões esparsas nas regiões Norte (Manaus, Rio Branco, Boa Vista, Macapá principalmente) e Nordeste e oeste da Bahia. A disponibilidade de motocicletas individualiza o Centro-Oeste, onde o uso deste meio de transporte é bem adaptado às condições precárias das estradas e aos níveis de renda mais baixos da população.

Por outro lado, a população menos equipada que a média concentra-se em todas as microrregiões da região Norte e todo o grande sertão do Nordeste. A população menos equipada que a média, menos de motocicletas, concentra-se no interior, coincidindo com o tristemente famoso Polígono das Secas, figura recorrente da pobreza no país.

Esta figura indica que a realidade se transformou não se pode mais falar de dois "Brasis", mas de quatro ou cinco. Este contexto brasileiro, baseado em dados de 2010, reforça o índice de desenvolvimento humano (IDH) de 2011 para o Brasil: 84o lugar entre 187 países avaliados $(0,718$ em 1,0) segundo o Relatório de Desenvolvimento Humano do PNUD.

Apesar de estar classificada em $84^{\circ}$ lugar, a posição do Brasil como um todo tem mostrado avanços. Nas primeiras aplicações do índice de desenvolvimento humano (IDH) para os Estados brasileiros, a análise regionalizada das condições de acesso à educação saúde e renda tinha reforçado, ainda mais, a constatação da forte desigualdade social brasileira. Uma visão que os dados de 2010 confirmam.

Ainda que haja críticas ao uso indiscriminado desta metodologia, sua aplicação permitiu uma visualização do posicionamento dos países na escala global. Entre os anos 1980 e 1990 tinhase dois Brasis. Já em 1996 identificavam-se três regiões distintas: os mais altos índices (0,8 ou mais) na região centro-sul: Distrito Federal, Minas Gerais, Espírito Santo, Rio de Janeiro, São Paulo, Mato Grosso do Sul, Paraná, Santa Catarina e Rio Grande do Sul. Para os índices entre 0,7 e 0,8 situavam-se os Estados de Goiás, Mato Grosso, Bahia, Pará, Amapá, Amazonas e Acre. Entre 0,3 e 0,5 os Estados do Ceará, Rio Grande do Norte, Pernambuco. Ao reaplicar a metodologia para os dados de 2000, cinco classes foram estabelecidas: na primeira, de 0,779 a 0,844 encontravam o Distrito Federal e os Estados do Rio De Janeiro, São Paulo, Paraná, Santa Catarina, Rio Grande do Sul; na segundo classe, de 0,747 a 0,778 os 
estados do Espírito Santo, Minas Gerais, Mato Grosso do Sul, Goiás e Mato Grosso. Na terceira categoria, de 0,706 a 0,746 o Tocantins, Pará, Amazonas, Rondônia, Roraima e Amapá; na quarta categoria $(0,683$ a 0,705$)$ os Estados da Bahia, Pernambuco, Rio Grande do Norte e Ceará e na quinta categoria $(0,636$ a 0,682) apenas 5 estados, Sergipe, Alagoas, Paraíba, Piauí e Maranhão.

A modificação desta realidade vem ocorrendo por meio de políticas redistributivas, como a Bolsa Família. Iniciada como Bolsa-Escola em Campinas (SP) em 1994, difundida e complementada pelo programa poupança-escola de Cristovam Buarque, quando governador do Distrito Federal (1995-1999), em 2001 passou a integrar as ações do governo federal. Ao mesmo tempo, existiam outros programas de transferência de renda, idealizados pela Comunidade Solidária como a bolsa alimentação, o cartão alimentação e o auxílio-gás no governo de Fernando Henrique Cardoso (1995-2002). Enquanto bolsa-escola, o governo do Distrito Federal garantia um salario mínimo para as famílias carentes que tivessem crianças entre 7 e 14 anos matriculados em escola pública, aos quais se aplicavam como critérios para recebimento do auxilio a frequência mensal mínima de $90 \%$, a residência no DF de pelo menos 5 anos e a renda per capita da família inferior a meio salario mínimo. No final de 2002 eram beneficiadas 5 (cinco) milhões de famílias.

No primeiro mandato do Presidente Luiz Inácio "Lula" da Silva (2003-2006) houve a integração destes benefícios e das ações do programa Fome Zero no programa Bolsa Família. O conceito foi ampliado de maneira a criar uma renda mínima para famílias que contavam com gestantes, nutrizes, crianças ou adolescentes e dispunham de uma renda per capita mensal de $\mathrm{R} \$ 70,01$ a $\mathrm{R} \$ 140,00$.

Esta política de transferência de renda continuou aumentando sua área de atuação, incluindo no governo da Presidente Dilma Rousseff (2011-2014), a primeira infância, por meio do programa Brasil carinhoso. Atualmente o número de beneficiários é de 13,77 milhões de famílias (www.brasil.gov.br, setembro 2012), as quais devem, como contrapartidas, comprovar a frequência escolar mínima (baixou para $85 \%$ e para os jovens de 16 e 17 anos, 75\%) além de informações sobre atendimento à saúde das crianças menores de 7 anos (pesagem e vacinas). 


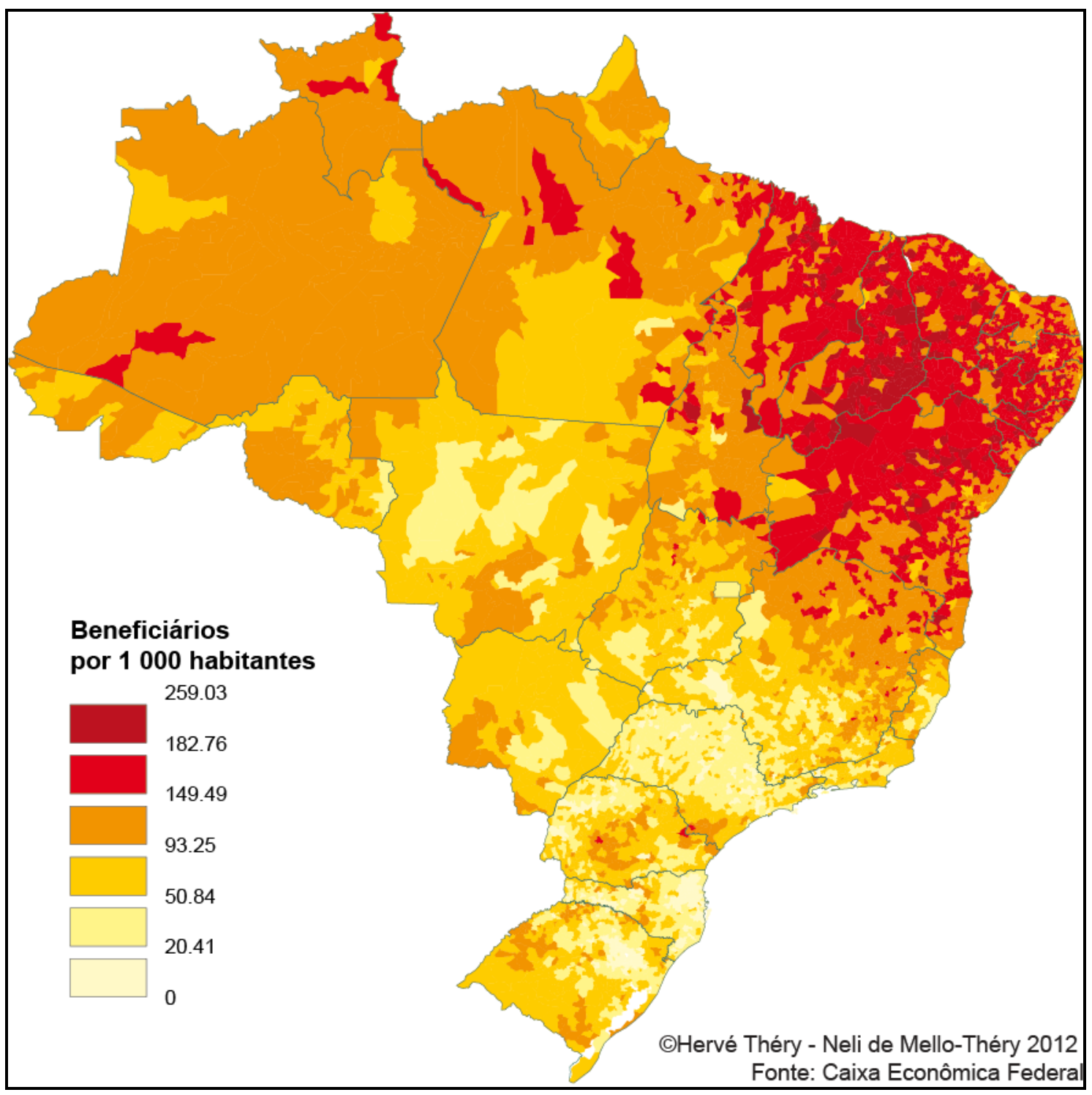

Figura 4 Beneficiários da Bolsa família

O mapa dos beneficiários por 1000 habitantes revela uma forte disparidade entre as regiões Nordeste e o resto do país. Fica evidente o peso dessa política nos nove estados do nordeste brasileiro quando se comparam as imagens das figuras $n^{\circ} 3$ e 4 . É ainda a região onde 0 benefício é extremamente significativo atingindo entre 150 a 260 beneficiários em cada 1000 habitantes. Inversamente é nas regiões sul, sudeste (exceto o Polígono das Secas) e centro oeste que se vê a mais baixa relação de beneficiários por 1000 habitantes (de nenhum até 50 favorecidos).

Ao Norte do país predomina a categoria de 100 e 150 beneficiários por 1000 habitantes, embora se destaquem algumas municipalidades nos estados do Pará e Amazonas como mais dependentes, nas quais a relação é de 150 a 180 beneficiários em 1000 habitantes.

Não é de nosso interesse apresentar neste artigo uma análise intrínseca da política social de transferência de renda, a diversidade de temáticas relacionadas à analise da bolsa família 
pode ser identificada por meio de uma pesquisa no sistema Scielo-Brasil: em agricultura e em especial no Nordeste (Duarte, Sampaio, Sampaio, 2009; Melo e Duarte, 2012; Santos et al. 2010), na saúde (Trevisani, Burlandy e Jaime, 2012; Traldi, Almeida e Ferrante, 2012), nos direitos humanos (Zimmermann, 2006), institucional (Licio, Mesquita e Curralero, 2011; Senna et al., 2007), eleitoral (Moura, 2007; Druck e Filgueiras, 2007; Marques e Mendes, 2007; Marques et al. 2009; Licio, Rennó e Castro, 2009; Soares e Terron, 2008), proteção social e cidadania (Costa, 2009; Rego, 2008), desenvolvimento (Kerstenetzky, 2009), transferência de renda (Medeiros, Britto e Soares, 2007; Bichir, 2010) e percepção social (Castro et al, 2009).

Nossa abordagem realça o aspecto da disparidade territorial da abrangência desta ação pública, enfatizando a necessidade de transformar as regiões onde ela se concentra em um espaço menos dependente de políticas assistencialistas. A economia de hoje gera postos em serviços, atualmente são novas ocupações em serviços que garantem a ascensão social. A questão principal é a discussão do papel do Estado e o Brasil segue no dilema: apostar em atividades que permitirão ao país produzir produtos de alto valor e conhecimento agregados ou continuar exportando commodities, mitigando os efeitos excluentes via um política de transferências financeiras aos mais pobres?

Neste mesmo contexto, a imagem seguinte aponta o que o governo chama de "reforma agrária”, ou seja, o numero de famílias assentadas no país até 2012. O diretor do IPEA, Marcio Pochman, afirma que a atual estrutura agraria do país é pior que a de 1920 (http://www.viomundo.com.br/entrevistas/marcio-pochmann-despolitizada-nova-classemedia-e-desafio-para-partidos-e-sindicatos.html), pois 40 mil proprietários concentram $50 \%$ das áreas agricultáveis do país.

Em artigos anteriores já havíamos afirmado que a concentração de projetos de assentamentos agrários na região norte se, por um lado atendia uma demanda dirigida do movimento dos sem-terra, segundo o discurso governamental, de outro, significava o seu deslocamento das regiões onde viviam para áreas longe do mercado. A decisão por esta estratégia representa simplesmente uma questão de custo, bem mais reduzido, porque as terras disponíveis estavam em poder do Estado (federal ou estados-membros). 


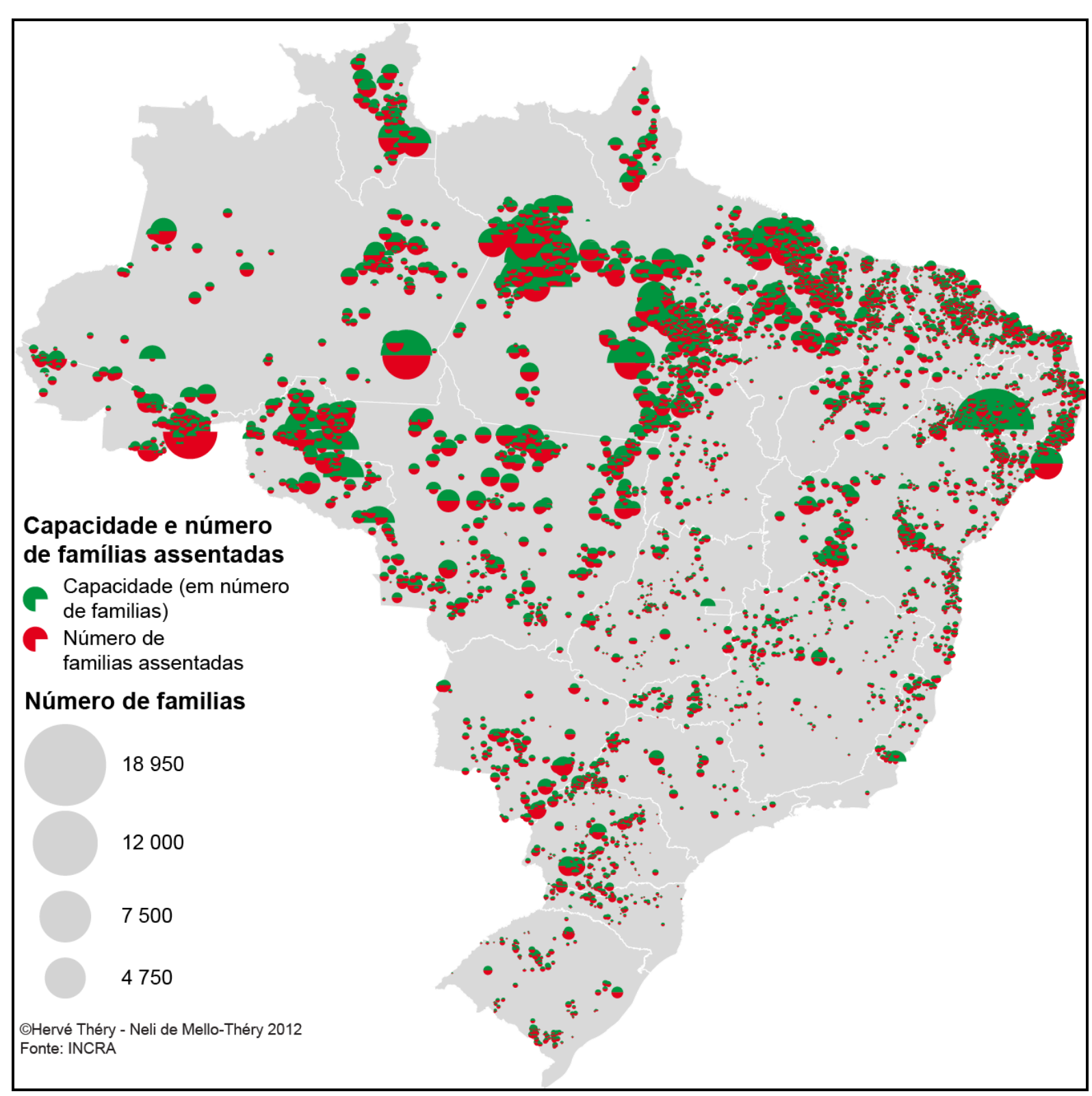

Figura 5 Assentamentos do INCRA

Em geral por todo o país, a área utilizada para os assentamentos sempre projeta um número de famílias a serem assentadas sempre a maior, medindo-se pela capacidade do assentamento.

Neste caso, o pior é que a maioria dos assentamentos possui capacidade ociosa e que acaba representando uma perda de terra e uma perda do ecossistema atingido. Grosso modo, as áreas destinadas à reforma agrária absorvem bem menos famílias do que previsto, sendo que algumas exceções podem ser identificadas no Acre, no Mato Grosso do Sul. Por outro lado, em algumas áreas no Nordeste do país, identificam-se assentamentos cuja capacidade é muitíssimo menor do que o numero de famílias atendidas. 
Apesar de pouca divulgação nos últimos anos, a política de assentamentos agrários tem continuado a instalar na Amazônia a maioria de seus projetos. Entre 1995 e 2002, no governo de Fernando Henrique Cardoso esta diretriz representou o atendimento de aproximadamente $37 \%$ do total de assentamentos. Considerando-se dados do INCRA de 2012, ainda que em toda a região o processo continuasse, o estado do Amazonas foi o que mais implantou projetos.

Neste contexto, além da problemática de deslocamento das famílias que demandam a propriedade da terra, voltamos a enfatizar o grande conflito territorial entre política agrária e política de conservação ambiental. Existem, no Norte do país, tantas famílias demandantes ou o deslocamento de regiões "quentes" para regiões distantes continua sendo a estratégia governamental?

As disparidades podem também ser identificadas por meio da dependência do emprego público e das transferências entre municípios ricos e pobres.

Da maneira semelhante às variáveis anteriores, a distribuição espacial do numero de funcionais ativos da administração municipal direta marca algumas localidades: a maior densidade de funcionários ativos por 10 mil habitantes ocorre ainda no estado do Rio de Janeiro, seguido pelos estados da região Nordeste, onde representam uma relação que varia entre 375 a 918 funcionários por 10 mil habitantes. Importante destacar que, embora em as capitais estaduais apresentem um alto número em valores absolutos, eles são menos importantes em valores relativos.

O grande peso dos funcionários ocorre nas municipalidades do interior da região, demonstrando a importância dos empregos governamentais no total do emprego gerado. Verifica-se o mesmo fato na região Norte, especialmente no estado do Amazonas. 0 fenômeno da falta de dinamismo torna-as áreas perdedoras no conjunto da economia e do desenvolvimento local. A questão que emerge é que consiste o governo em o único empregador? Neste contexto, as dinâmicas territoriais estão, obviamente, interligadas ao desempenho da ação paternalista governamental. Se o governo deixasse de gerar empregos, como a outra economia funcionaria? 


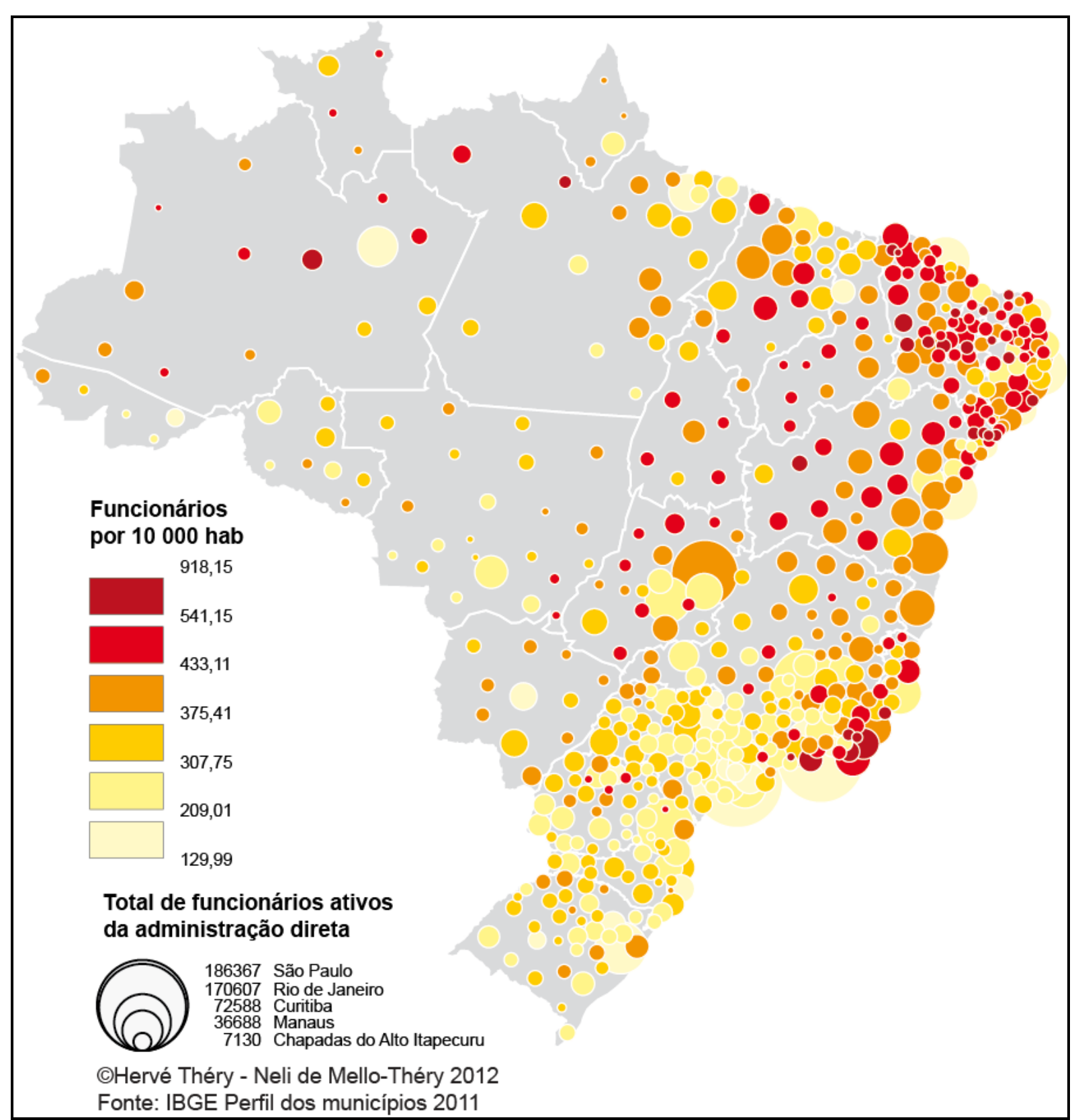

Figura 6 Funcionários municipais

A mesma dúvida surge ao se analisar as transferências financeiras do Fundo de participação dos municípios (FPM): para boa parte do país - a maior parte do Nordeste, o litoral da Amazônia, a quase totalidade do Tocantins e de Minas Gerais (exceto as regiões de Belo Horizonte e do Triângulo mineiro), as regiões periféricas de Goiás e dos três Estados meridionais, mais de $40 \%$ das receitas municipais provêm de transferências financeiras do Fundo de Participação Municipal (FPM), chegando a mais de 55\% para os mais dependentes. O mesmo criterio destaca, na outra ponta da distribuição estatística com menos de $20 \%$ das receitas ligadas a transferências, os estados de Rio de Janeiro e Espírito Santo (graças às royalties do petróleo) a parte central e oriental do Estado de São Paulo. O Centro-Oeste e a 
Amazônia estão na mesma situação graças à renda derivada da exploração excessiva dos recursos naturais (madeira, soja, minérios) e à baixa densidade de população.

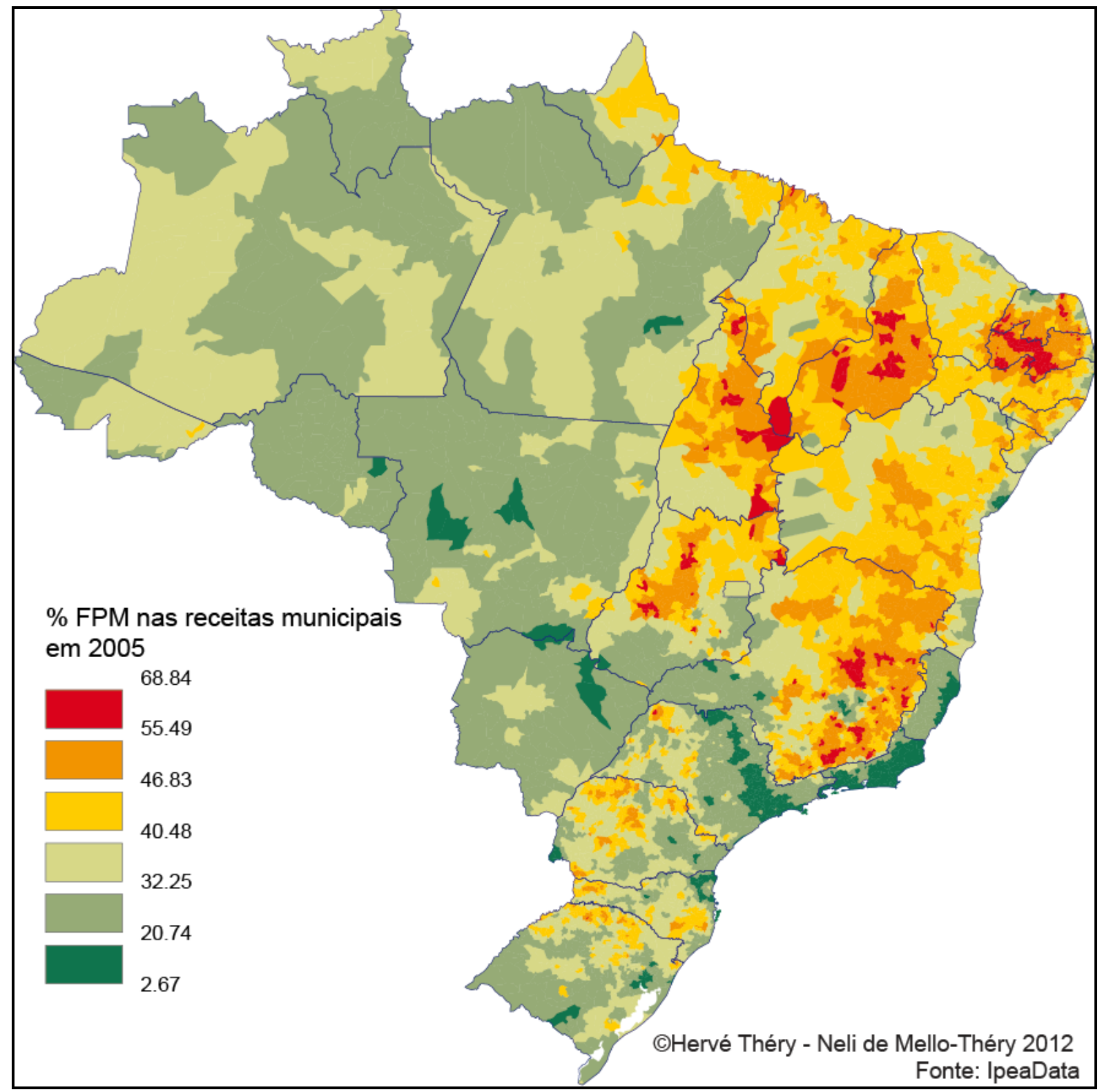

Figura 7 Transferências do FPM

A situação destas regiões pioneiras é menos favorável quanto à capacidade de poupança, que se concentra maciçamente no Sudeste, como demonstra a figura $n^{\circ} 8$ : um mapa em anamorfose onde a superficie de cada microregião é modificada em função da variável analisada, neste caso o volume de poupança depositado nos bancos. 


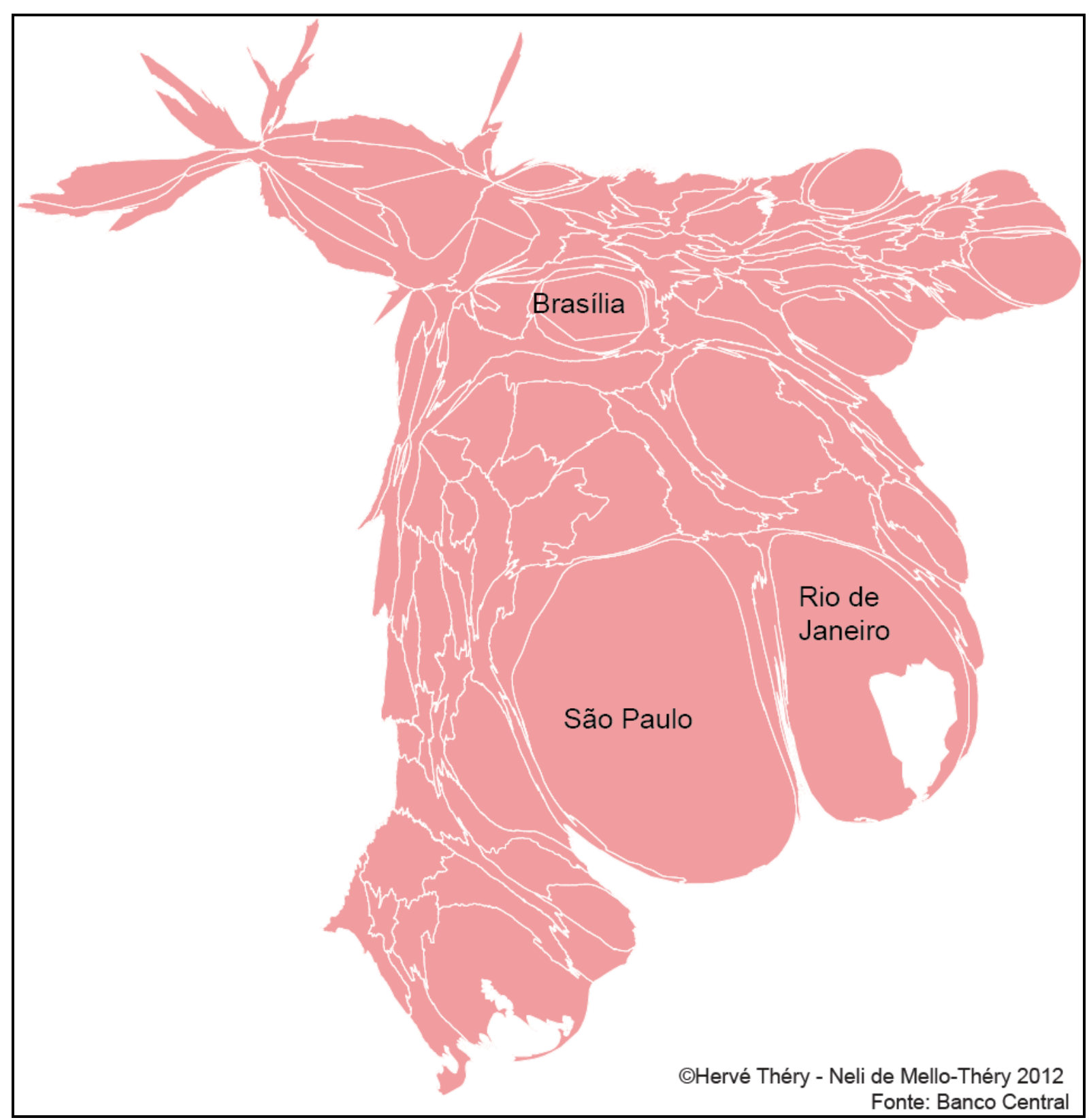

Figura 8 Poupança

A imagem sublinha o peso de São Paulo e Rio de Janeiro, assim como do Distrito federal e de algumas capitais do Sul, Sudeste e Centro-Oeste. Porém, nos estados nortistas e nordestinos o volume da poupança é de reduzidíssima importância, o que, nesta forma de representação, provoca o "encolhimento" e até o quase desaparecimento de seus territórios.

Finalmente, uma análise fatorial permite, ao juntar vários tipos de informação, observar semelhanças e oposições entre os municípios do país para as variáveis escolhidas entre luitas outras como sendo as mais discriminantes. No plano fatorial da figura $n^{\circ} 9$, construido usando os fatores 1 (39,62\% da variação) e 2 (12,68\%), aparecem agrupamentos 
significativos de variáveis, que determinam tipos de municípios de características semelhantes.

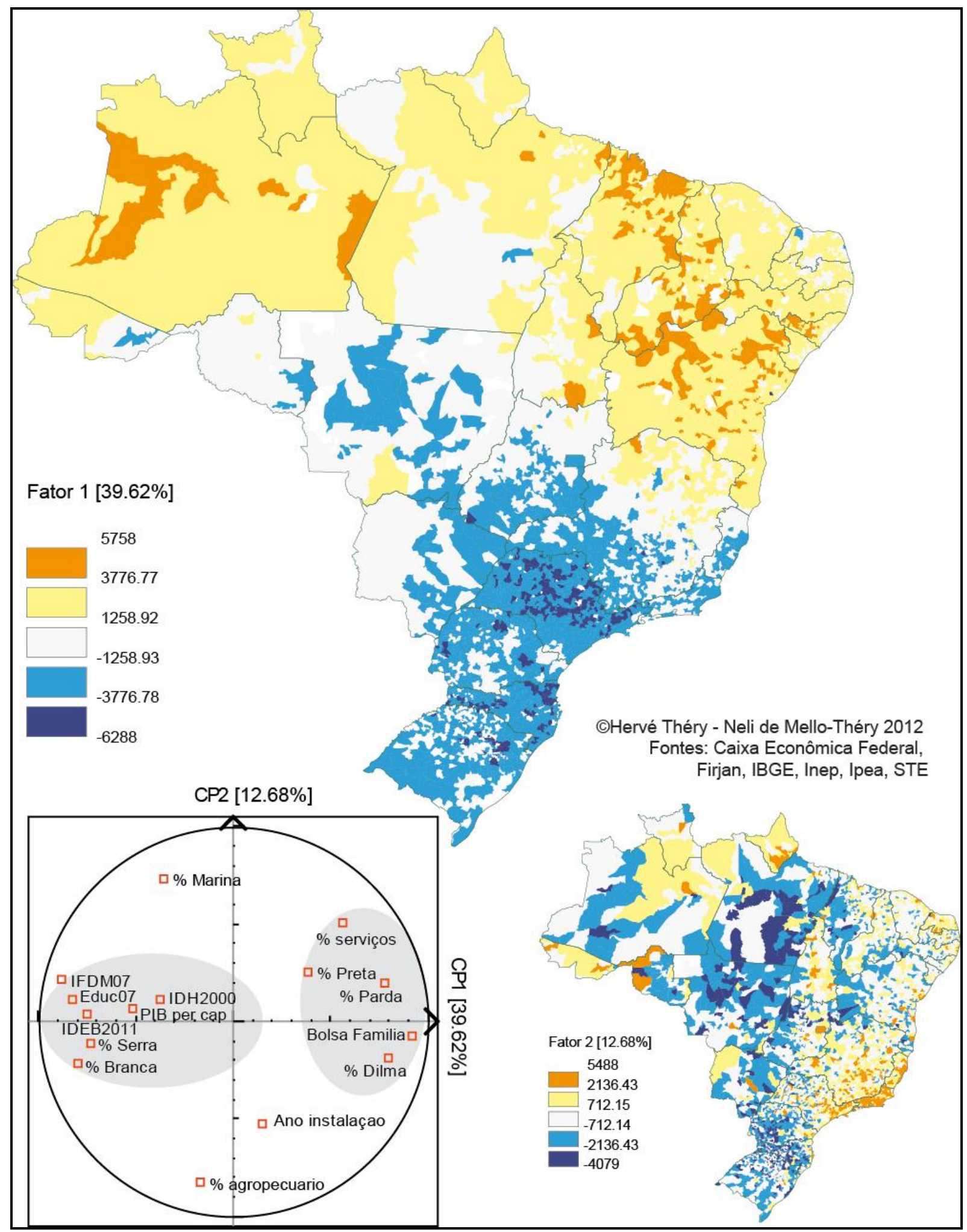

Figura 9 Análise fatorial das disparidades territoriais. 
$\mathrm{Na}$ esquerda do gráfico (indicando valores negativos para o fator 1) os municípios têm PIB per capita alto, bons resultados no IDH, IFDM (Índice Firjan de Desenvolvimento Municipal) e IDEB (Educação), uma alta proporção da população é de pele branca e votou para José Serra na eleição presidencial de 2010. Do lado direito (valores positivos para o fator 1 ) uma alta proporção do PIB dos municípios vem dos serviços (ou seja os setores agropecuário e industrial pesam pouco), as cores de pele dominantes são preto e pardo, o número de beneficiários da Bolsa família é elevado e o candidato preferido na eleição presidencial foi Dilma Rousseff. Como consequência, o mapa que representa os resultados dos municípios neste eixo do fator 1 (mapa principal da figura $n^{\circ} 9$ ) opõe claramente de um lado o Nordeste e a Amazônia (menos Rondônia e o sul do Pará) e de outro o Sudeste, o Sul e o Centro-Oeste (com as regiões amazônicas citadas). Este contraste reforçaria a idéia dos "dois Brasis", desde que se junte ao primeiro todo o Centro-Oeste, o qual aparece cada vez mais como um prolongamento do Sudeste.

O fator 2 destaca, de cima para baixo no plano fatorial e no segundo mapa da figura 9, variáveis relacionadas com as franjas pioneiras, de um lado (valores negativos, parte baixa do gráfico e cores frias no mapa) e o seu oposto (valores positivos, parte alta do gráfico e cores quentes no mapa): entre as primeiras encontram-se a proporção do setor agropecuário no PIB municipal, o ano recente de instalação do município e o voto favorável a José Serra. Parece ter uma adequação entre as ideias do candidato Serra e a mentalidade pioneira, ou uma rejeição das ideias de Dilma e Lula nesta região.

\section{DISCUSSÃO}

Continua o desenvolvimento brasileiro marcado pelas desigualdades sociais e territoriais, fruto das opções conservadoras e de um modelo que excluía a maioria da população? Um modelo que optou pela exportação de commodities ou de recursos naturais sem agregação de valor? Continuaremos sendo o "celeiro" do mundo ou passaremos a desenvolver tecnologia e inovações, reconhecendo a necessidade de se ter uma população mais qualificada?

Quantas décadas ainda manteremos as dinâmicas territoriais, notadamente a dinâmica da fronteira, que avança continuamente e transforma e organiza as terras novas conquistadas? Se o mesmo permanece impulsado dessa dinâmica da fronteira, o destino das regiões mais antigas na conquista do território é a se transformarem em regiões perdedoras? 
Os dados censitários (2000 e 2010) apontam que ao longo dos últimos dez anos, algumas estratégias governamentais que fortalecem essas dinâmicas:

$\checkmark \quad$ O crescente aumento na produção de riqueza no país só significa desenvolvimento quando toda a sociedade tem acesso aos bens dai resultantes. A produção de riqueza aumentou, transformando o país na 6o maior economia mundo, mas apesar desses avanços, quando se considera o IDH o Brasil ainda é o 20 país da América Latina, sua media sendo inferior vários países do continente, classifica bem atrás do Chile (44ㅇ),

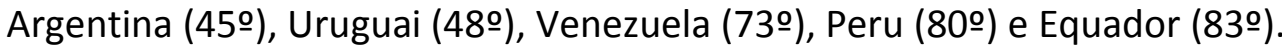

$\checkmark$ No caso brasileiro, a riqueza ainda permanece concentrada em mãos de alguns segmentos sociais, pois quando se analisa - entre outras - as variáveis de acesso a bens, equipamentos e serviços, a imagem do país ainda é aquela dos três Brasis: um centro sul desenvolvido, no qual os domicílios são mais bem equipados do que a média; uma região centro-norte onde as moradias são um pouco mais equipadas que a média e finalmente, uma terceira região que abrange todo o Norte e o Nordeste onde as residências são menos equipadas do que a média nacional.

$\checkmark$ Os meios de comunicação brasileiros têm promovido o discurso de acesso aos bens materiais da nova classe média brasileira. Marcio Pochman questiona a ascensão e a despolitização deste novo segmento de classe, cuja amplitude de renda é enorme (entre R\$ 200,00 e 1500). Na apresentação do livro Nova Classe Média? O trabalho na base da pirâmide social brasileira ele suscita a duvida:

"Seja pelo nível de rendimento, seja pelo tipo de ocupação, seja pelo perfil e atributos pessoais, o grosso da população emergente não se encaixa em critérios sérios e objetivos que possam ser claramente identificados como classe média".

$\checkmark$ Em entrevistas, Pochman tem problematizado a questão: a classe média é formada por segmentos com ocupação de bancários, professores, advogados; ela ganha, gasta e poupa; seus gastos são em cultura, entretenimento, educação. O que esta sendo chamado de nova classe média é um segmento dentro da classe trabalhadora, que não possui patrimônios e cujos novos gastos são encaminhados apenas para o consumo. Onde estão sendo criados postos de trabalho? Nos anos 70 a economia cresceu com a indústria, a $10 \%$ ao ano.

$\checkmark \quad$ No caso da Bolsa família como política redistributiva de renda, o crescimento também foi espetacular: de cinco milhões de famílias beneficiadas em 2002 para 13,77 milhões 
em setembro de 2012. Essa política enfatiza a grande disparidade territorial entre as regiões ao norte e ao sul do país, destacando três regiões: nordeste, norte e centro-sul, sendo a região nordeste onde é mais significativo o peso dos beneficiários da Bolsa família e o centro-sul onde a relação beneficiário-habitante é baixa.

$\checkmark \quad$ Esta política só terá sido uma vitória se dentro de alguns anos esse esforço resultar em outras condições de desenvolvimento humano, com maior assistência à saúde, menor dependência da população, redução das condições de analfabetismo funcional e melhores condições de renda para a maioria dos cidadãos.

$\checkmark$ No caso da concessão de terras novas aos sem-terra a estratégia do Estado brasileiro foi utilizar um capital fundiário importante que detém em seu poder para atender suas demandas (e reduzir os processos reivindicatórios). Parece permanecer a lógica, dos anos 1970, de doar "as terras sem homens aos homens sem terra". Permanece a tendência de implantá-los na Amazônia. Basta ver o crescimento acentuado da tendência de implantação dos novos projetos de assentamentos agrários no interior do estado do Amazonas, locais que até os anos 2000 estavam protegidos da pressão antrópica da frente pioneira.

$\checkmark$ Além disso, existe capacidade ociosa em praticamente todos os projetos, o que resulta em perda do solo e da biodiversidade. Os ecossistemas atingidos, notadamente a floresta amazônica tem sido degradados sem que nenhuma melhoria do índice de desenvolvimento social ou mesmo de aumento de produção agrícola originada nestes projetos realmente apareça.

$\checkmark \quad$ O peso dos funcionários de administração municipal e do FPM nas finanças municipais em algumas regiões brasileiras é mais um indicador que aponta a dependência da ação do Estado nas antigas "terras", perdedoras no jogo da mundialização atual. Este indicador reforça e destaca o peso das desigualdades nos dois Brasis: aquele dependente da transferência de recursos da União para municípios (entre $40 \%$ e mais de 55\%), com o qual coincide o emprego nas instituições estatais, provavelmente, resultante da reduzida dinâmica da atividade econômica local.

$\checkmark$ Contrariamente, a capacidade de poupança é o retrato oposto da transferência de recursos: além dos estados de São Paulo e Rio de Janeiro, apenas em algumas microrregiões ao sul, sudeste e centro-oeste do país a poupança é significativa. 
Finalmente a análise fatorial ao mesmo tempo reativa a dicotomia dos "dois Brasis" rico e pobre, desenvolvido e subdesenvolvido - com a grande diferença em relação à situação de trinta anos atrás que todo o Centro-Oeste foi incorporado ao primeiro. Porém, fica claro que ela não é mais suficiente para caracterisar as disparidades do país e menos ainda suas dinâmicas, e que convem levar em conta pelo menos uma transformação de grande porte, a presença do "arco do sesmatamento", ao longo do qual progride a frente pioneira, com as suas produções típicas (soja mecanizado, pecuária extensiva) e as suas mentalidades específicas marcadas - entre outros traços por um comportamento político conservador.

\section{CONCLUSÕES}

O uso da cartografia temática, baseada na analise estatística, como método de investigação e interpretação do dinamismo espacial do Brasil é uma abordagem que permite compreender a realidade brasileira, enfatizando os contrastes do território, seus condicionantes, suas tendências e seus movimentos dominantes.

Assim, a partir da utilização de dados de fontes distintas e atuais, como censos demográficos, perfis municipais, beneficiários da Bolsa Família, entre outros, procuramos entender a evolução da sociedade brasileira e o significado das mudanças, pois estas se expressam no tempo e no espaço. A ação de distintos atores sobre fatores ligados ao processo de desenvolvimento do país ressaltam novas estruturas territoriais: de um país de contraste norte-sul, pobre e rico, para um país mais diverso, no qual os avanços econômicos começam a transparecer também em evoluções do IDH, da poupança. Como um país de contrastes, onde grandes regiões não são autônomas, mas dependem da ação do Estado. Um país onde as "terras novas" e os recursos estão se esgotando, o que o obrigará a cuidar muito mais do seu capital natural para que o mesmo possa servir ao seu próprio desenvolvimento econômico e social, sem destruição.

\section{REFERÊNCIAS BIBLIOGRÁFICAS}

ACSERALD, Henri (org.). Cartografia social e Dinâmicas Territoriais: marcos para o debate. Rio de Janeiro. IPPUR/UFRJ. 2010. 
BRUNET, Roger. Le développement des territoires. Le Moulin du Château: Éditions de l'Aube. 2004.

ECKERT, Dennis. Évaluation et prospective des territoires. Paris: Reclus,1996.

FERRÃO, João. Dinâmicas territoriais e trajectórias de desenvolvimento: Portugal 1991 2001. http://poolman.no.sapo.pt/Trajec desenvol.pdf

MONBEIG, Pierre. Pionniers et planteurs de l'État de São Paulo, Paris: Librairie Armand Colin,1952.

MONBEIG , Pierre. "Les mouvements pionniers en Amérique Latine » In Les phénomènes de "frontière " dans les pays tropicaux, colloque en l'honneur de Pierre Monbeig, 1979, Paris. Travaux et Mémoires de IHEAL, $n^{\circ} 34,1981$, p.49-58.

SMITH, Neil. Gentrificação, a fronteira e a reestruturação do espaço urbano. In GEOUSP. Espaço e Tempo, São Paulo, n²1, pp. 15-31, 2007.

THÉRY, Hervé e DE MELLO, Neli. Atlas do Brasil: Disparidades e dinâmicas do território, EDUSP, 2005.

THÉRY, Hervé. Le Brésil, Armand Colin, 6a edição atualizada 2012 (1a edição 1985).

TURNER, Frederick Jackson. The Frontier in American History. New York: Henri Holt and Company. 1935.

VERDI, Adriana Renata e PIRES, Elson Luciano Silva. As dinâmicas territoriais locais na globalização: aspectos conceituais e metodológicos. Florianópolis : Geosul, v.23, n.46, 2008. pp. 33-53.

RELATORIO DE DESENVOLVIMENTO HUMANO. http://www.pnud.org.br/IDH/DH.aspx (consultado em 10 de outubro de 2012). 